\title{
Leak rate quantification method for gas pressure seals with controlled pressure differential
}

\author{
Christopher C. Daniels ${ }^{1}$, Minel J. Braun ${ }^{2}$, Heather A. Oravec ${ }^{3}$, and Janice L. Mather ${ }^{4}$ \\ The University of Akron, Akron, OH 44325-3901 \\ Shawn C. Taylor ${ }^{5}$ \\ The University of Toledo, Toledo, $\mathrm{OH} 43606$
}

\begin{abstract}
An enhancement to the pressure decay leak rate method with mass point analysis solved deficiencies in the standard method. By adding a control system, a constant gas pressure differential across the test article was maintained. As a result, the desired pressure condition was met at the onset of the test, and the mass leak rate and measurement uncertainty were computed in real-time. The data acquisition and control system were programmed to automatically stop when specified criteria were met. Typically, the test was stopped when a specified level of measurement uncertainty was attained. Using silicone O-ring test articles, the new method was compared with the standard method that permitted the downstream pressure to be non-constant atmospheric pressure. The two methods recorded comparable leak rates, but the new method recorded leak rates with significantly lower measurement uncertainty, statistical variance, and test duration. Utilizing this new method in leak rate quantification, projects will reduce cost and schedule, improve test results, and ease interpretation between data sets.
\end{abstract}

\section{Nomenclature}

$\begin{array}{lll}a_{0} & = & \text { zero-order regression coefficient } \\ a_{1} & = & \text { first-order regression coefficient } \\ a_{n} & = & \mathrm{n}^{\text {th }} \text {-order regression coefficient } \\ \beta & = & \text { bias error } \\ i, k & = & \text { indices } \\ m & = & \text { mass } \\ \dot{m} & = & \text { mass leak rate } \\ N & = & \text { number of samples } \\ p & = & \text { absolute pressure } \\ \phi & = & \text { precision error } \\ R & = & \text { specific gas constant } \\ \rho & = & \text { correlation coefficient } \\ T & = & \text { temperature } \\ t & = & \text { uncertainty } \\ U & = & \text { volume }\end{array}$

\footnotetext{
${ }^{1}$ Associate Research Professor, Department of Mechanical Engineering, AIAA Senior Member.

${ }^{2}$ Distinguished Professor, Department of Mechanical Engineering.

${ }^{3}$ Research Assistant Professor, College of Engineering, AIAA Member.

${ }^{4}$ Senior Research Engineer, College of Engineering.

${ }^{5}$ Senior Research Associate, Mech., Ind. and Manufacturing Engineering, AIAA Senior Member.
} 


\section{Introduction}

Elastomer gas pressure seals have long been used to confine breathing air inside space vehicles, ${ }^{1}$ with silicone compounds predominantly utilized for their temperature performance and reusability. ${ }^{2}$ Unfortunately, silicone seals have a high relative leak rate due to the compound's permeability. ${ }^{2-4}$ The overall leak rate rises even further when the sealing surface is degraded from on-orbit atomic oxygen impingement, ${ }^{4-7}$ ultraviolet radiation exposure, ${ }^{4}$ micrometeoroids and orbital debris impacts, ${ }^{8,9}$ and foreign object debris and lunar dust contamination. ${ }^{10-12}$

As the leak rate performance of the gas pressure seals dictates the quantity and weight of resources required to replenish breathing air, lengthy and costly developmental programs are undertaken for each seal design considered for use in space. These research efforts quantify the leak rate within the seal's anticipated operational envelope to determine the conditions of maximum leak rate and the leak rate at common operational conditions. Since multiple tests may be conducted to achieve statistical significance or to reduce experimental uncertainty, large quantities of leak rate tests are often required as demonstrated in numerous studies. ${ }^{13,14}$

Using the "test as you fly" philosophy in designing development programs, it is desirable to determine the leak rate of air through the test article. Reducing margins by utilizing test methods with quantifiable and low measurement uncertainty may be of interest. While technical considerations should be the main factors in choosing a leak rate quantification method, a method's hardware cost may become important when budgets are limited. To reduce project schedule and manpower cost, minimizing a test's duration is often desirable.

Many acceptable methods exist for measuring leak rates of various magnitudes. ${ }^{15,16}$ For seals used in space habitat applications, two methods are most typically used depending upon the size of the leak and the gas to be measured. One method is the pressure decay method with mass point leak rate analysis. ${ }^{17}$ The test apparatus consists of a hermetically sealed volume of gas, except for the test article. The apparatus is pressurized with an ideal gas and is allowed to leak through the test article. The gas pressure and temperature are recorded over time. The mass of gas within the system is calculated using the ideal gas law. The mass of the gas is calculated at an arbitrary number of time-steps yielding a mass-time data set $\left(t_{i}, m_{i}\right)$. A best-fit line to the data is computed using a linear least-squares regression centered about the differential pressure of interest. The first-order coefficient of the best-fit line represents the leak rate of the test article.

The pressure decay method with mass point leak rate analysis may be applied to a wide range of leak rates, and a reasonable measurement uncertainty can be achieved. ${ }^{18}$ The method utilizes low cost equipment, mainly temperature and pressure measurement devices, and any ideal gas of interest may be characterized. The high-pressure side of the test article includes an internal volume of gas while the low-pressure side may be an applied vacuum. A more simple apparatus configuration allows laboratory pressure to be downstream of the test article, though the analysis becomes more complicated when the barometric pressure varies. Though the method takes temperature into account by using the measurement in the computation, the method remains temperature sensitive. The temperature used in the calculations must accurately represent the gas temperature, which may be challenging to accomplish. The duration of the leak test using the pressure decay method may vary depending upon the combination of test article leak rate and the size of the internal volume.

The other commonly used leak rate quantification method is the helium (or other tracer gas) leak detector method. Using this method, the apparatus is pressurized with helium on the interior of the test article. The low-pressure side of the test article is vacuum pressure and is connected to a leak detector (i.e., mass spectrometer). The gases that are transported past the test article are electrically charged in the detector. The detector's mass spectrometer associates the abundance of tracer gas ions with a volumetric flow rate of helium. The leak rate from a helium leak detector test is reported in volumetric flow rate of helium which has to be converted to mass flow rate of air for application to space habitat seals; the conversion process is not constant, nor trivial, as it is dependent upon the geometry of the leak paths within the test article. This test technique can provide excellent results for very small volumetric flow rates, but becomes impractical for large flow rates as the pressure at the mass spectrometer must be approximately $10 \mathrm{mtorr}$ or below. This impracticality includes situations when the size of the seal becomes too great, as the leak rate increases linearly with seal length for seals of identical geometry and material (e.g., O-rings). The tracer gas leak detector method requires expensive equipment and properly trained personnel. The detector calibration process should be completed during every test trial and extends the length of the test, but the test duration is not necessarily lengthy.

Both commonly used leak rate methods have potential advantages and drawbacks when used to develop space seal performance data. Until now, there was no method that had all of the desired attributes: capability to quantify small and large leak rates, assign a reasonable level of uncertainty, utilize air as the test gas, and maintain short test durations with leak rates and associated uncertainty calculated in real-time. This paper describes a novel method to 
quantify the leak rate of seals for space application that minimizes development cost and schedule. The method shortens otherwise long duration tests, utilizes low-cost hardware and instrumentation so it can be replicated in multiple test stands, has quantifiable and controllable measurement uncertainty, and requires no data post-processing. Advantages of the enhanced method are highlighted herein with a comparison of silicone O-ring seal leak rates quantified using the new system to rates obtained through application of the standard mass point leak rate method with uncontrolled downstream pressure.

\section{Description of the test method}

The new test method was similar to the standard pressure decay method with mass point leak rate analysis, but with one significant enhancement. A control system was used to maintain the desired pressure differential across the test article throughout the test by raising or lowering the downstream pressure. This enhancement, while seemingly small, made substantial changes to the application of the method.

Similar to a standard pressure decay-type leak rate measurement system, the test apparatus consisted of a hermetically sealed volume of gas, except for the test article whose leak rate quantity was of interest. The apparatus was pressurized with the test gas and was allowed to leak past the test article. The low-pressure region, previously a constant or uncontrolled barometric pressure when

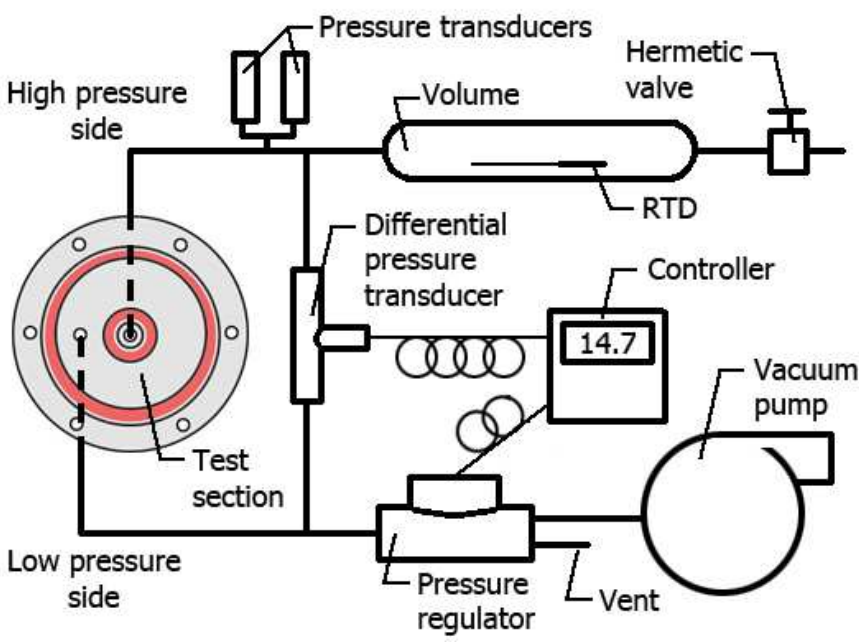

Figure 1. Schematic of the test apparatus. the standard method was employed, was controlled such that a differential pressure across the test article was maintained at the desired constant value throughout the test. This differential pressure was measured using a differential pressure transducer of suitable range, see Fig. 1. As the pressure of the high-pressure region decreased due to leakage past the test article, the pressure in the low-pressure region was reduced by a similar value to maintain the constant differential pressure, as illustrated in Fig. 2. This eliminated the potential for exceedingly long test duration due to a disproportionately low leak rate for the system, see Fig. 3(A), wherein the differential pressure would never meet the target. It also extended the test duration for tests of high leak rate test articles, see Fig. 3(B),

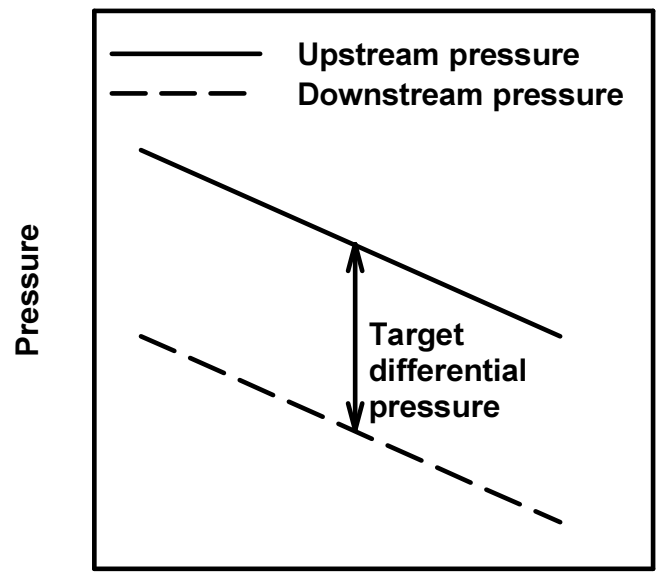

Time

Figure 2. Illustration of pressure behavior of the high- and low-pressure sides of the test article.

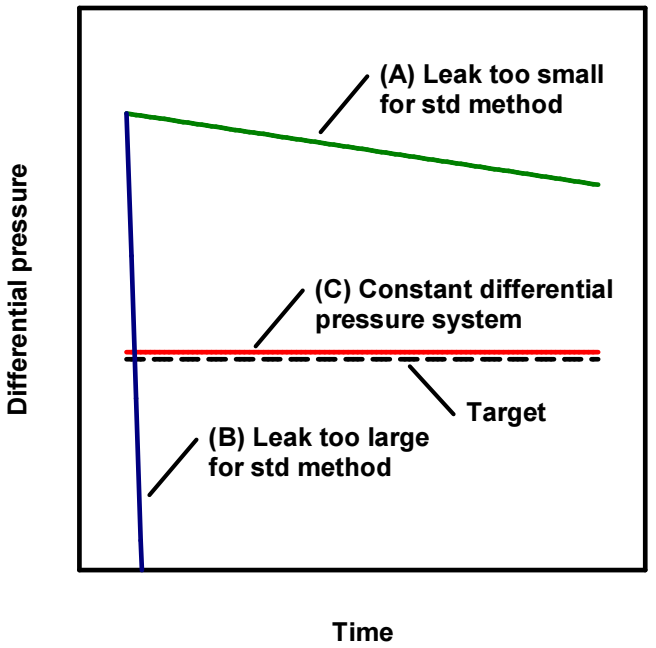

Figure 3. Illustration of the intended performance of the constant differential pressure leak rate system compared with that of the standard system. 
thereby allowing for improved measurement uncertainty. A constant differential throughout the duration of the test resulted, see Fig. 3(C).

A controller managed the activity of the pressure regulator. The input value from the differential pressure transducer was compared to the desired set point. Using a proportional-integral control algorithm, the controller sent a voltage signal to the pressure regulator, with connections to both an ambient pressure vent and vacuum, to raise or lower the downstream pressure as appropriate to obtain the desired pressure differential across the test article.

The gas pressure and temperature within the high-pressure side volume were recorded over time. Using Boyle's law, the volume was quantified in advance. ${ }^{19}$ Similar to the standard pressure decay method with mass point leak rate data analysis and uncontrolled downstream pressure, the ideal gas law was assumed and the mass of gas within the system was calculated using Eqn. 1 for each time-step yielding a mass-time data set $\left(t_{i}, m_{i}\right)$.

$$
m=\frac{p V}{R T}
$$

Since the differential pressure across the test article was the desired value throughout the duration of the test, a linear least-squares regression was computed for the entire data set using Eqn. 2.

$$
m(t)=a_{1} t+a_{0}
$$

The uncertainty of mass loss was calculated ${ }^{17}$ using the generalized Eqn. 3.

$$
\begin{aligned}
& U_{\dot{m}}^{2}=\sum_{i=1}^{N}\left(\frac{\partial \dot{m}}{\partial m_{i}}\right)^{2} \beta_{m_{i}}^{2}+\sum_{i=1}^{N}\left(\frac{\partial \dot{m}}{\partial t_{i}}\right)^{2} \beta_{t_{i}}^{2}+\sum_{i=1}^{N}\left(\frac{\partial \dot{m}}{\partial m_{i}}\right)^{2} \phi_{m_{i}}^{2}+\sum_{i=1}^{N}\left(\frac{\partial \dot{m}}{\partial t_{i}}\right)^{2} \phi_{t_{i}}^{2} \\
& +2 \sum_{i=1}^{N-1} \sum_{k=i+1}^{N}\left(\frac{\partial \dot{m}}{\partial m_{i}}\right)\left(\frac{\partial \dot{m}}{\partial m_{k}}\right) \rho_{m_{i} m_{k}} \beta_{m_{i}} \beta_{m_{k}}+2 \sum_{i=1}^{N-1} \sum_{k=i+1}^{N}\left(\frac{\partial \dot{m}}{\partial t_{i}}\right)\left(\frac{\partial \dot{m}}{\partial t_{k}}\right) \rho_{t_{i} t_{k}} \beta_{t_{i}} \beta_{t_{k}} \\
& +2 \sum_{i=1}^{N-1} \sum_{k=i+1}^{N}\left(\frac{\partial \dot{m}}{\partial t_{i}}\right)\left(\frac{\partial \dot{m}}{\partial m_{k}}\right) \rho_{t_{i} m_{k}} \beta_{t_{i}} \beta_{m_{k}}
\end{aligned}
$$

Applying the assumption that any error in the time measurement was negligible $\left(\beta_{t_{i}}=\phi_{t_{i}}=0\right)$ and utilizing correlation coefficients $\left(\rho_{m_{i} m_{k}}=0\right)$ that produced the maximum uncertainty ${ }^{17}$, Eqn. 3 simplified to Eqn. 4 .

$$
U_{\dot{m}}^{2}=\sum_{i=1}^{N}\left(\frac{\partial \dot{m}}{\partial m_{i}}\right)^{2} \beta_{m_{i}}^{2}+\sum_{i=1}^{N}\left(\frac{\partial \dot{m}}{\partial m_{i}}\right)^{2} \phi_{m_{i}}^{2}
$$

where,

$$
\begin{gathered}
\beta_{m}^{2}=\left(\frac{V}{R T} \beta_{p}\right)^{2}+\left(\frac{p}{R T} \beta_{V}\right)^{2}+\left(\frac{p V}{T} \beta_{R}\right)^{2}+\left(\frac{p V}{R} \beta_{T}\right)^{2} \\
\phi_{m}^{2}=\left(\frac{V}{R T} \phi_{p}\right)^{2}+\left(\frac{p}{R T} \phi_{V}\right)^{2}+\left(\frac{p V}{T} \phi_{R}\right)^{2}+\left(\frac{p V}{R} \phi_{T}\right)^{2}
\end{gathered}
$$

and

$$
\frac{\partial \dot{m}}{\partial m_{i}}=\frac{N t_{i}-\sum_{i=1}^{N} t_{i}}{N \sum_{i=1}^{N}\left(t_{i}^{2}\right)-\left(\sum_{i=1}^{N}\left(t_{i}\right)\right)^{2}}
$$

Whereas the standard analysis method calculates the leak rate using Eqn. 2 after the test has concluded, the enhanced method is capable of computing the leak rate and associated uncertainty (using Eqns. 2-5) at each time step in real-time.

\section{Experimental hardware setup}

To compare the performance of the enhanced and standard leak rate methods, similar experimental test setups were used to measure the leak rates of a series of similar test articles. The test hardware is described below.

\section{A. Test installation}

The test section used with the enhanced test method was comprised of two test platens manufactured from stainless steel, each with surface roughness better than $0.4 \mu \mathrm{m}$. The test article was installed into a standard O-ring groove $^{2}$ in the bottom platen and compressed against the flat surface of the top platen, Figs. 4 and 5. The platens 


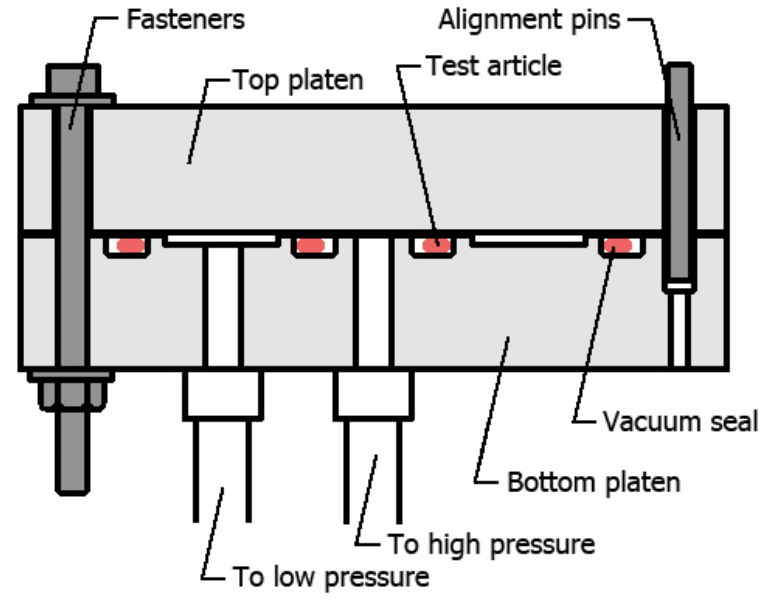

Figure 4. Diagram of the test section cross-section.

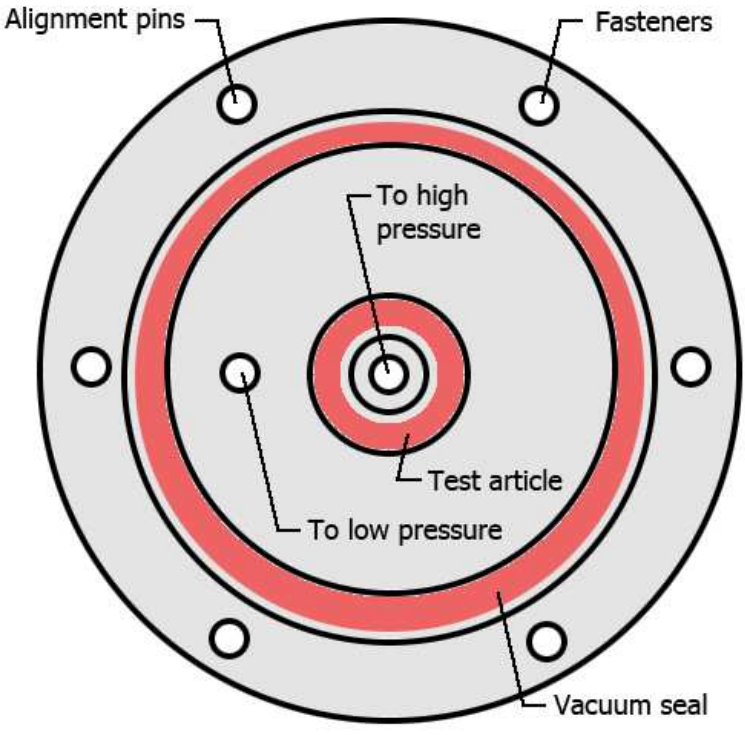

Figure 5. Diagram of the test section.

were assembled such that each test article was compressed by $25 \%$ of its nominal height. The test gas used was dry air and was supplied to the test article's interior from the high-pressure side of the apparatus at approximately $124 \mathrm{kPa}$. During testing with the enhanced method, the control system reduced the pressure on the low-pressure side of the apparatus until the pressure differential across the seal was $101 \mathrm{kPa}$.

The mass loss calculations were computed by the data acquisition and control system using gas properties on the high-pressure side of the test apparatus and Eqns. 1 and 2. The gas pressure was monitored using two pressure transducers. The average of the two readings at each time step was used in the computations. The temperature was monitored using a Class A accuracy resistance temperature detector (RTD) attached to the external surface of the volume, see Fig. 1. The volume of the high-pressure side was determined using an average of 248 applications of Boyle's law (i.e., $p_{1} V_{1}=p_{2} V_{2}$ ). The size of the volume was approximately $70.59 \mathrm{ml}$ for each of the three test setups used to collect the data.

The bias and precision errors used in Eqn. 5 were unique to each of the three test apparatus used during the study. Each error was obtained using each instrument's calibration records (e.g., pressure transducers), product specifications (e.g., RTD), or computations (e.g., the volume). A table of representative values is presented for the reader's understanding in Table 1.

To minimize differences between the temperature measurements and the actual gas temperature, the test section, pressure transducers, volume, RTD, and hermetic valve were contained within an environmental control chamber. The intended test temperature was $23^{\circ} \mathrm{C}$.

The test section used to implement the standard method was very similar to the hardware used with the enhanced method; however, there were some key differences. Instead of being connected to the control system, the lowpressure port was vented to the ambient laboratory environment and the vacuum seal was removed. In this configuration, air leaked past the test article directly into the ambient laboratory environment. To achieve the same nominal pressure differential across the test article created using the enhanced method, the high-pressure air supply used with the standard test method was increased to approximately $200 \mathrm{kPa}$. The system was allowed to leak, lowering the pressure differential, until $101 \mathrm{kPa}$ was achieved. The similar pressure differential across the test article facilitated a comparison of leak rate results for replicate seals evaluated using the two respective test methods.

Table 1. Representative values of bias and precision errors.

\begin{tabular}{|l|l|l|}
\hline Instrument & $\begin{array}{l}\text { Bias } \\
\text { error }\end{array}$ & $\begin{array}{l}\text { Precision } \\
\text { error }\end{array}$ \\
\hline Pressure transducer & $26 \mathrm{~Pa}$ & $9.7 \mathrm{~Pa}$ \\
\hline RTD & $0.196^{\circ} \mathrm{C}$ & $0.022^{\circ} \mathrm{C}$ \\
\hline Volume & $2.131 \mathrm{ml}$ & $0.392 \mathrm{ml}$ \\
\hline
\end{tabular}

Table 2. Nominal dimensions of the test articles.

\section{B. Test articles}

\begin{tabular}{|l|l|}
\hline Inner diameter, $\mathbf{m m}$ & Thickness, $\mathbf{m m}$ \\
\hline $10.5 \pm 0.127$ & $5.33 \pm 0.127$ \\
\hline
\end{tabular}


The test articles were standard AS568A size 2-309 O-rings manufactured from S0383-70 silicone elastomer compound by Parker Hannifin Corporation. The nominal dimensions of the specimens are shown in Table 2. The samples were cleaned with isopropyl alcohol and allowed to air dry. They were tested in an as-manufactured state, without protectant or lubrication applied. Six test articles were evaluated using the enhanced method, and six test articles were evaluated using the standard method for comparison.

\section{Data acquisition system}

A computer-based data acquisition system collected the pressure and temperature measurements at a rate of approximately $10 \mathrm{~Hz}$. When implementing the enhanced method, pressure and temperature measurements were combined with the previously quantified volume to compute the mass of gas at each time-step. The history of mass computations was used to compute the leak rate and its associated uncertainty in real-time throughout the duration of the test. The software allowed the system to run continuously as long as the pressure differential did not decrease by $6.9 \mathrm{kPa}$ due to insufficient high-pressure side gas supply. The test continued until the mass loss measurement uncertainty was below $10 \%$, with a minimum duration of five minutes and a maximum of 24 hours.

When implementing the standard method, pressure and temperature measurements were collected at similar sample rates. The system was allowed to run until the operator estimated sufficient data was collected. Finally, the leak rate and associated uncertainty were computed after the test was completed.

\section{Results and discussion}

The mass of dry air, leak rate, and measurement uncertainty for a typical test article evaluated using the enhanced method are shown in Figs. 6 and 7. The characteristics of these curves were typical, but values were dependent upon the instruments used, their bias and precision errors, the specimen leak rate, the stability of the temperature, and the volume size. The main feature of this enhanced test method, the controlled pressure differential, was programmed to be $101.35 \mathrm{kPa}$ for each test. During the particular test shown in Figs. 6 and 7, the differential pressure oscillated between 101.14 and $101.28 \mathrm{kPa}$. The small fluctuations were included in each timestep's leak rate calculation, but were considered an insignificant influence on the leak rate through the test article.

During the first hour of the test, the computed value of leak rate varied significantly due to the combination of scatter in the pressure and temperature instrumentation measurements and the short time interval, see Fig. 7. Unrealistically large and negative leak rate values were common. As expected, the corresponding uncertainties were very large due to the large variation in computed leak rate. As the test continued, the loss of mass in the volume and the time duration became more significant than the scatter, and the measurement uncertainty was reduced. It should be noted that the leak rate for the test article was assumed to be constant during the course of the experiment, only the computed value of leak rate changed.

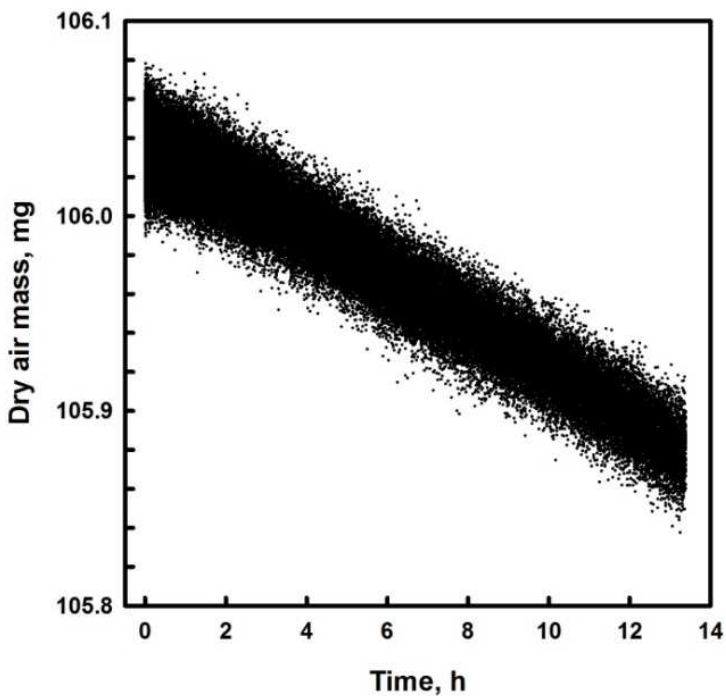

Figure 6. Typical mass response.

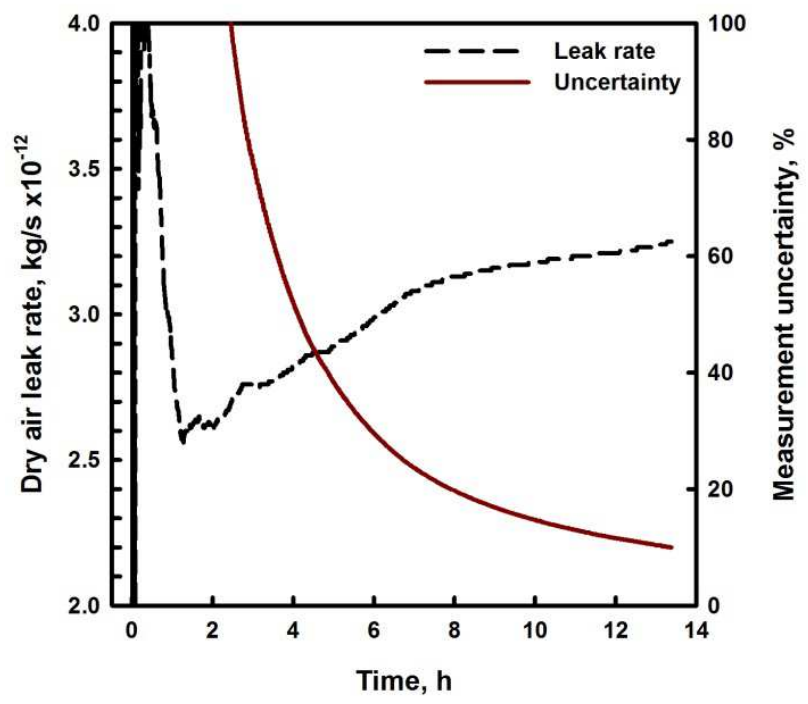

Figure 7. Typical response of leak rate calculation and measurement uncertainty. 
Each of the tests was stopped automatically when the uncertainty was below $10 \%$ of the leak rate. The leak rates of six replicate test articles were determined, see Fig. 8. The result was an average leak rate of $3.27 \times 10^{-12} \mathrm{~kg} / \mathrm{s}$. The standard deviation, which quantifies the dispersion of measurements, was $0.68 \times 10^{-12} \mathrm{~kg} / \mathrm{s}$. The test durations ranged from 10 to 18 hours.

The level of measurement uncertainty at which to stop was arbitrarily set to $10 \%$. Other acceptable levels could have been chosen which would have resulted in different test durations, see Table 3.

The data collected for the six additional replicate test articles used to compare the leak rate results of a standard uncontrolled pressure mass point leak rate system required extensive manual post-processing, as described in Ref. 17. During the post-process calculation of leak rate, the largest interval of data was utilized that was (a) centered about the differential pressure of $101.4 \mathrm{kPa}$, and (b) did not exhibit significant curvature in the mass-time data set. ${ }^{17}$ This generally produces the smallest (and most desirable) value of measurement uncertainty. The results for those six tests are plotted in Fig. 9. The mean of calculated leak rates was $3.63 \times 10^{-12} \mathrm{~kg} / \mathrm{s}$ with a standard deviation of $1.61 \times 10^{-12} \mathrm{~kg} / \mathrm{s}$. The test durations ranged between 45 and 65 total hours. Since the desired pressure differential $(101.4 \mathrm{kPa})$ was not met during most of the test, between three and 10 hours of data was used for the leak rate computations. The data recorded before and after was discarded. The resultant measurement uncertainties were between 23 and $82 \%$.

Upon comparing the variation in the seal leak rates determined using the two individual systems, it was noted that measurement standard deviation was decreased by approximately half through implementation of the enhanced method to control the pressure differential across the test article. When the enhanced method was used, test duration was reduced such that one test per work day could be completed, compared with one test every two to three days when using the standard method. In addition, measurement uncertainty was controlled and greatly improved, by up to $88 \%$, in tests where the enhanced method was employed.

When using a system that does not employ a downstream pressure controller, the gas leaks past the test article and into uncontrolled ambient or constant vacuum pressure. The test duration is dictated by the time necessary to reach the desired differential pressure. The measurement uncertainty is controlled by the amount of time the system is near the desired differential pressure. This time may be very short for high leak rate test articles and for periods of rising barometric pressure, as illustrated in Fig. 3. This time

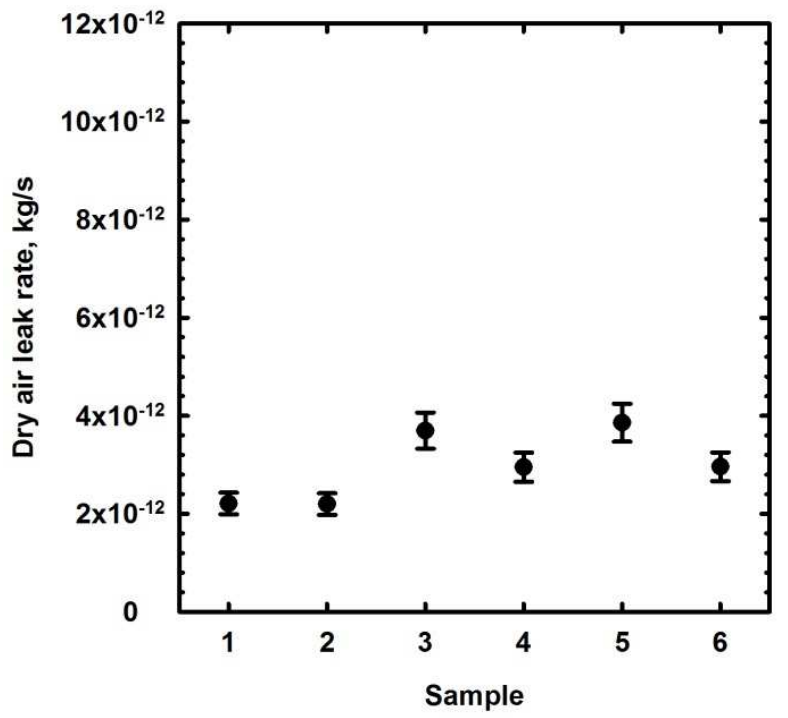

Figure 8. Leak rates of test articles using controlled pressure differential test system. Error bars represent measurement uncertainty of each trial computed individually using Eqns. 3-5.

Table 3. Measurement uncertainty and typical corresponding test duration.

\begin{tabular}{|c|c|}
\hline $\begin{array}{l}\text { Measurement } \\
\text { uncertainty, \% }\end{array}$ & $\begin{array}{l}\text { Test } \\
\text { duration, } \mathbf{h}\end{array}$ \\
\hline 30 & 5.9 \\
\hline 20 & 7.9 \\
\hline 10 & 13.4 \\
\hline
\end{tabular}

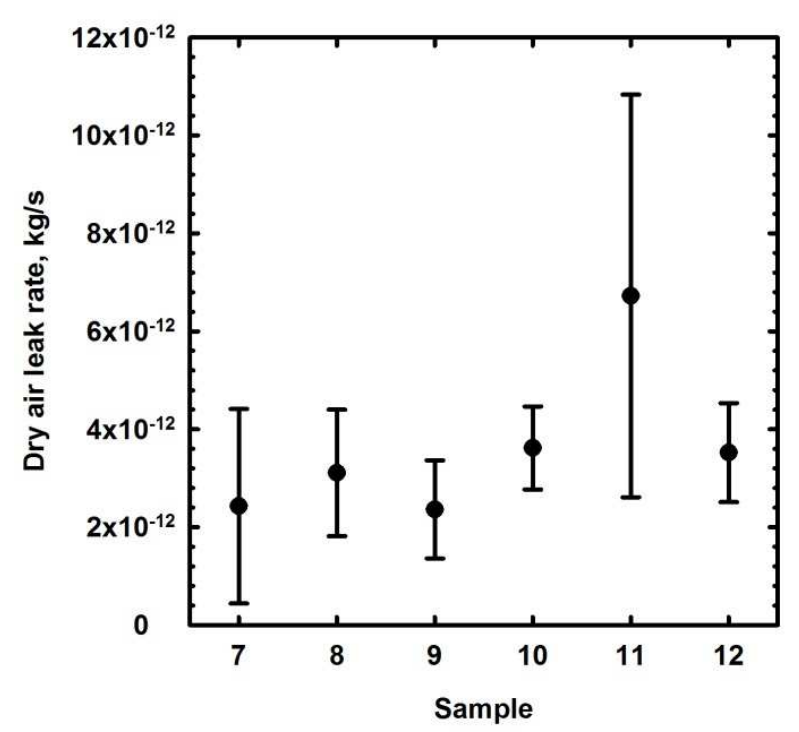

Figure 9. Leak rates of test articles using standard uncontrolled pressure mass point leak rate method. Error bars represent measurement uncertainty of each trial computed individually using Eqns. 3-5. 
may be very long for low leak rate test articles and for periods of falling atmospheric pressure. In an unfortunate situation, the leak rate may be similar to the falling barometric pressure and the system may "chase" the desired differential pressure for days.

By utilizing a controller and maintaining the desired pressure differential, all the data acquired was available to compute the test article's leak rate. The test duration was predominantly dependent upon the desired measurement uncertainty; however, leak rate and high-pressure side volume size were very important. Controlling the measurement uncertainty eased data interpretation as each test was run until the same uncertainty was obtained. The appearance of the data conveyed confidence that the experiments were well controlled, since the error bars were similar in magnitude, as in Fig. 8. The comparison between data sets as data points was also eased as each datum point was afforded equal weighting. This may not be the case for data with disproportionately large measurement uncertainty, (e.g., sample 11 in Fig. 9).

\section{Conclusions}

A new method to quantify the leak rate of a silicone elastomer test article for space application was presented. An enhancement to the standard pressure decay method with mass point leak rate analysis was made by adding a differential pressure control system. The addition of a control system provided a constant pressure differential across the test article by raising or lowering the downstream gas pressure, as appropriate. The test duration was not extended waiting for the desired pressure differential to occur. As a result, the mass leak rate and measurement uncertainty were computed in real-time. The overall test duration was greatly reduced as the test was programmed to automatically stop when specified criteria were met; most importantly, the test was stopped when a predefined level of measurement uncertainty was met. The method with enhancement was compared with a method that permitted the downstream pressure to be uncontrolled atmospheric pressure by measuring the leak rate of AS568A size 2-309 silicone O-rings. Similar leak rate values were computed from both methods. When compared to the results of the standard method, the results computed by the new method had significantly lower measurement uncertainty, $10 \%$ compared to $23-82 \%$; lower standard deviation, $0.68 \times 10^{-12} \mathrm{~kg} / \mathrm{s}$ compared to $1.61 \times 10^{-12} \mathrm{~kg} / \mathrm{s}$; and shorter test duration, a single day compared with two to three days. Implementation of this enhanced leak rate method into developmental spaceflight programs may lead to reduced project schedule and cost while improving the quality and reliability of the obtained data.

\section{References}

\footnotetext{
${ }^{1}$ Finkbeiner, J., Dunlap P., Steinetz, B., and Daniels, C., "Design review of seals on the Apollo spacecraft," Journal of Spacecraft and Rockets. Vol. 45, No. 5 (2008): 900-910.

${ }^{2}$ Parker Hannifin Corporation. Parker O-ring handbook. Parker Hannifin Corporation, Cleveland, Ohio, 2001.

${ }^{3}$ Peacock, R.N., "Practical selection of elastomer materials for vacuum seals," Journal of Vacuum Science and Technology. Vol. 17, Issue 1 (1980): 330-336.

${ }^{4}$ Linton, R.C., Finckenor, M.M., Kamenetzky, R.R., and Gray, P., "Effects of atomic oxygen and ultraviolet radiation on candidate elastomeric materials for long-duration missions: Test series No. 1," NASA/TM-108408 (1993).

${ }^{5}$ Daniels, C.C., Wasowski, J.L., Panickar, M.B., and Smith, I.M., "Leak rate performance of three silicone elastomer compounds after ground-simulated and on-orbit environmental exposures," Proceedings of the $3^{\text {rd }}$ AIAA Atmospheric Space Environments Conference. 27-30 June 2011, Honolulu, Hawaii. AIAA 2011-3823 (2011).

${ }^{6}$ Penney, N., Wasowski, J.L., and Daniels, C.C., "Temperature and atomic oxygen effects on helium leak rates of a candidate main interface seal," Proceedings of the 46 th AIAA/ASME/SAE/ASEE Joint Propulsion Conference. 25-28 Jul 2010, Nashville, Tennessee. AIAA 2010-6986 (2010).

${ }^{7}$ Christensen, J.R., Underwood, S.D., Kamenetzky, R.R., and Vaughn, J.A., "Atomic oxygen effects on seal leakage," Proceedings of the 20th Space Simulation Conference: The Changing Testing Paradigm; 27-29 Oct. 1998, Annapolis, MD and NASA/CP 1999-208598 (1999): 195-206.

${ }^{8}$ de Groh III, H.C., Gallo, C.A., and Nahra, H.K., "Meteoroid and orbital debris threats to NASA's docking seals: Initial assessment and methodology," AIAA-2009-3524. Proceedings of the AIAA 1st Atmospheric and Space Environments Conference. San Antonio, Texas, June 22-25, 2009.

${ }^{9}$ de Groh III, H.C., and Steinetz, B.M., "Effects of hypervelocity impacts on silicone elastomer seals and mating aluminum surfaces," AIAA-2009-5249. Proceedings of the 45th AIAA/ASME/SAE/ASEE Joint Propulsion Conference \& Exhibit. Denver, Colorado, 2-5 Aug, 2009.

${ }^{10}$ Garafolo, N.G., and Daniels, C.C., "Contamination simulation of elastomer space seals with foreign object debris," Proceedings of the $3^{\text {rd }}$ AIAA Atmospheric Space Environments Conference. 27-30 June 2011, Honolulu, Hawaii. AIAA 2011-3823 (2011).
} 
${ }^{11}$ Gaier, J.R., "The effects of lunar dust on EVA systems during the Apollo missions," NASA/TM 2005-213610 (2005).

${ }^{12}$ Oravec, H.A., and Daniels, C., "Leak rate performance of silicone elastomer O-rings contaminated with JSC-1A lunar regolith simulant," 14th ASCE International Conference on Engineering, Science, Construction and Operations in Challenging Environments, 27-29 October. St. Louis, MO.

${ }^{13}$ Garafolo, N.G., and Daniels, C.C., "Experimental investigation of the leak-rate performance of a subscale composite elastomer-retainer docking seal," Journal of Spacecraft and Rockets. Vol. 50, No. 3 (2013): 709-714.

${ }^{14}$ Smith, I. M., Daniels, C. C., Dunlap, P. H., and Steinetz, B. M., "Performance of sub-scale docking seals under simulated temperature conditions," Proceedings of the 44th AIAA/ASME / SAE / ASEE Joint Propulsion Conference \& Exhibit, 21-23 Jul 2008. Hartford, CT. AIAA 2008-4713 (2008).

${ }^{15}$ National Aeronautics and Space Administration, "Constellation program environmental qualification and acceptance testing requirements (CEQATR)," CxP 70036 Rev. C. 5-Oct 2009: 36-40.

${ }^{16}$ Moore, P.O., Jackson, Jr., C.N., and Sherlock, C.N., editors, Nondestructive Testing Handbook, Leak Testing, Vol. 1, American Society for Nondestructive Testing, Inc., 3rd ed., 1998.

${ }^{17}$ Garafolo, N.G., and Daniels, C.C., "Mass point leak rate technique with uncertainty analysis," Research in Nondestructive Evaluation. 25 (2) 2014: 125-149.

${ }^{18}$ Daniels, C.C. and Garafolo, N.G., "Comprehensive mass point leak rate technique. Part II: Application of methodology and variable influences." Proceedings of the Fourth Japan - US Symposium Emerging NDE Capabilities for a Safer World, 7-11 Jun 2010. Maui, Hawaii, M4-5 (2010).

${ }^{19}$ Garafolo, N. G., "A compressible advection approach in permeation of elastomer space seals," Ph.D. Dissertation, Univ. of Akron, Akron, OH, 2010.

\section{Acknowledgements}

The authors wish to acknowledge Nicholas Penney of Ohio Aerospace Institute and Devin Dye of The University of Akron for their contributions to this work. Support for this work was provided by the National Aeronautics and Space Administration under contracts NNC08CA35C and NNC13BA10B. 